\title{
Transcriptional Regulation of RKIP Expression by Androgen in Prostate Cells
}

\author{
Honglai Zhang ${ }^{\mathrm{a}}$ Jianguo Wu ${ }^{\mathrm{b}}$ Jill M. Keller ${ }^{\mathrm{a}}$ Kam Yeung ${ }^{\mathrm{c}} \quad$ Evan T. Keller $^{\mathrm{a}}$ Zheng Fu ${ }^{\mathrm{b}}$ \\ aUniversity of Michigan Comprehensive Cancer Center and Department of Urology, University of \\ Michigan Health System, Ann Arbor, MI; ${ }^{b}$ Department of Human and Molecular Genetics, VCU Institute \\ of Molecular Medicine and VCU Massey Cancer Center, Virginia Commonwealth University, Richmond, \\ VA; 'Department of Biochemistry and Cancer Biology, College of Medicine, University of Toledo, Toledo, \\ $\mathrm{OH}$
}

\section{Key Words}

RKIP • Androgen • Androgen receptor • Prostate

\begin{abstract}
Background/Aims: Raf kinase inhibitory protein (RKIP) is a scaffolding molecule in the PEBP family that sequesters certain signaling molecules away from their pathways, thereby abrogating intracellular growth signals. RKIP has been assigned multiple functions and is associated with an increasing number of diseases through its involvement with signal transduction pathways. We previously demonstrated that RKIP is highly expressed in human normal prostate epithelial cells and plays a pivotal role during prostate cancer (PCa) progression. Whether RKIP is subject to endocrine regulation has not been reported. Methods: The effect of dihydrotestosterone (DHT) on RKIP expression in normal prostate epithelial cells was determined by real-time RTPCR and Western blot. Report assay was performed to determine whether the regulation of RKIP by androgens is at the transcriptional level. The binding of androgen receptor (AR) to the RKIP promoter was determined by EMSA and Chromatin Immunoprecipitation (ChIP) assays. To determine whether RKIP was regulated by androgen in vivo, we examined RKIP expression level in response to castration in 6-8 week old C57BL/6 male mice. Results: Here we report that DHT positively regulates the transcription of RKIP in the normal prostate epithelial cells. The anti-androgen bicalutamide blocked androgen-mediated regulation of RKIP, which indicates that this regulation is mediated through AR. Transfection of the cells with a RKIP promoter-driven luciferase reporter vector showed that DHT increased RKIP promoter activity in parallel with changes in expression. EMSA demonstrates that AR binds to a putative ARE in the RKIP promoter, which was further validated by ChIP assay. Importantly, these data are further supported by our in vivo experiment where castrated mice had less RKIP expression in their prostate glands than sham-operated mice. Conclusions: Collectively, the results establish RKIP as a novel androgen target gene. Androgens induce RKIP expression through AR-mediated transcriptional modulation of the RKIP promoter in the prostate. This is the first demonstration of endocrine regulation of the metastasis suppressor gene RKIP.
\end{abstract}

Copyright (C) 2012 S. Karger AG, Basel

Zheng Fu and Evan T. Keller

Department of Human and Molecular Genetics, Virginia Commonwealth University Richmond, VA 23298 (USA) and Department of Urology, University of Michigan Medical

School, 5304 CCC, 1500 E. Medical Center Dr. Ann Arbor, MI 48109-0940 (USA)

E-Mail zfu@vcu.edu and E-Mail etkeller@umich.edu 


\section{Introduction}

Raf kinase inhibitor protein (RKIP) is a member of phosphatidylethanolamine binding protein family (PEBP) [1]. The PEBP family of proteins is highly conserved and does not share sequence homology to proteins of known function [2]. We previously demonstrated that a PEBP homolog inhibits Raf-mediated activation of MEK [3], hence the name 'RKIP'. RKIP is a small, cytosolic protein originally purified from bovine brain [4-6]. RKIP is expressed abundantly in prostate and brain and is also present in liver, lung, testis, muscle and stomach [7-9].

RKIP appears to have a variety of functions depending on the tissue in which it is localized. Studies suggest that RKIP is involved in mammalian spermatogenesis and male fertility [8-10]. In rat medial septal nuclei, RKIP was found to enhance in vitro acetylcholine synthesis by up-regulating choline acetyltransferase and possible stimulation of cholinergic neuronal pathways [11]. RKIP was shown to have a role in lipid metabolism and phospholipids membrane biogenesis [12].

RKIP is also involved in several important cell signaling cascades. For example, RKIP was identified as a competitive inhibitor of Raf/MEK/ERK signaling [3,13]. It appears that RKIP acts to set the threshold for Raf- 1 activation and subsequent activation of MEK/ERK pathway. It has been shown that RKIP also antagonizes NF- $\mathrm{KB}$ signaling by interacting with several upstream kinases that regulate the IкB protein [14]. In addition, RKIP has a positive effect on G protein signaling by inhibiting G protein-coupled receptor kinase 2 (GRK-2), a critical negative feedback inhibitor of G protein-coupled receptors (GPCR) [15]. In contrast, RKIP was recently found to enhance signaling by glycogen synthase kinase-3 $\beta$ (GSK-3 $\beta$ ), a tumor suppressor that negatively regulates multiple oncogenic pathways including Wnt and cyclin D1 [16]. RKIP regulates GSK-3 $\beta$ and its substrates through oxidative stress-activated p38 mitogen-activated protein kinase. Furthermore, RKIP was shown to increase Kelch-like ECH-associated protein 1 (KEAP 1) stability in colorectal cancer tissues and HT29 CRC cell line [17]. KEAP1 is a substrate adaptor of a cullin 3-based E3 ubiquitin ligase complex that binds and degrades nuclear factor (erythroid-derived 2)-like 2 (NRF2), a transcription factor regulating oxidative stress.

Due to its involvement in several signaling pathways, RKIP is thought to modulate cellular functions that are dependent on or altered by these signaling pathways. We have previously identified that RKIP is abundantly expressed in the normal prostate epithelial cells $[18,19]$, implying that it may be closely associated with prostate development and prostate-related disease through its involvement with signal transduction pathways. Indeed, we demonstrated that RKIP plays a critical role during prostate cancer (PCa) progression $[18,19]$.

The prostate is an androgen-dependent organ due to the major regulatory functions of androgens in prostate development, growth, and function. Androgens exert their effect through the classic steroid receptor mechanism. Briefly, androgens bind to the androgen receptor protein with a very high affinity (in the nanomolar range) and induce a conformational change in the tertiary structure of the protein. The receptor then interacts with DNA and influences the transcription of target genes [20]. In this study, we sought to determine if androgen regulates expression of RKIP in the prostate.

\section{Materials and Methods}

\section{Cell culture}

RWPE-1, a human papillomavirus 18-immortalized non-tumorigenic prostate cell line was maintained in complete K-SFM medium (keratinocyte-serum free medium) (Invitrogen, Carlsbad, CA) which contains $50 \mu \mathrm{g} / \mathrm{ml}$ of BPE and $5 \mathrm{ng} / \mathrm{ml} \mathrm{EGF}$, plus antibiotic/antimycotic mixture (Penicillin, $100 \mathrm{U} / \mathrm{ml}$, Streptomycin $100 \mu \mathrm{g} / \mathrm{ml}$ and Fungizone, $25 \mu \mathrm{g} / \mathrm{ml}$ ). Cells were passaged upon confluence and seeded at $2 \times 10^{6}$ cells $/ \mathrm{T}-75$ flask. The cells were maintained in a humidified incubator with $5 \% \mathrm{CO}_{2}$ at $37^{\circ} \mathrm{C}$. 
RNA isolation and Real-time RT-PCR

For in vitro studies, RWPE-1 cells were plated in 6-well plates with complete K-SFM medium $24 \mathrm{~h}$ before treatment. For dose response experiments, RWPE- 1 cells were treated with vehicle $(0.001 \%$ DMSO) or with $0.01,0.1,1,5,10 \mathrm{nM}$ dihydrotestosterone (DHT) (dissolved in $0.001 \%$ DMSO, final concentration) for $24 \mathrm{~h}$. The effect of bicalutamide (Zeneca) on the regulation of RKIP expression by DHT was examined by treating the cells with vehicle $(0.001 \%$ DMSO) or with $10 \mu \mathrm{M}$ bicalutamide in the presence or absence of $5 \mathrm{nM}$ DHT for $24 \mathrm{~h}$. Bicalutamide was also solubilized in DMSO $(0.001 \%$, final concentration). The effect of cycloheximide on regulation of RKIP expression by androgen was tested by treating the cells with vehicle $(0.001 \%$ DMSO) or with $0.5 \mu \mathrm{g} / \mathrm{ml}$ cycloheximide in the presence or absence of $5 \mathrm{nM}$ DHT for $24 \mathrm{~h}$. Cycloheximide was also dissolved in $0.001 \%$ DMSO, final concentration). Cells were, then, harvested by removing the medium, washing the cells once with PBS and suspended in $1 \mathrm{~mL}$ of TRIzol Reagent (Invitrogen, Carlsbad, CA). For in vivo studies, tissues were homogenized in $1 \mathrm{~mL}$ of TRIzol Reagent using a pellet pestle (Kontes, Vineland, N)). Total RNA was isolated following the TRI Reagent protocol. RNA concentration was determined by absorbance at $260 \mathrm{~nm}$ using a UV spectrophotometer (Pharmacia Biotech, Uppsala, Sweden). $100 \mathrm{ng}$ of total RNA was utilized for real-time reverse transcription-polymerase chain reaction (RT-PCR) using QuantiTect SYBR Green RT-PCR kit (Valencia, CA). RT-PCR reactions were subjected to 45 cycles of $95^{\circ} \mathrm{C}$ for 15 seconds, $58{ }^{\circ} \mathrm{C}$ for 20 seconds, and $72{ }^{\circ} \mathrm{C}$ for 30 seconds. RT-PCR of $\beta$-globulin was used as an internal control to ensure equal loading of samples. We used oligonucleotide primers synthesized by Invitrogen to amplify a 400-base pair (bp) fragment of mouse RKIP RNA (forward primer: 5'-AACAGGCCCAGCGCATTTCAT-3'; reverse primer: 5'-ACAGCTTGGGCACATAGTCATC-3') and a 300-bp fragment of human RKIP RNA (forward primer: 5'- AGGACAGGCCGCTAAAGTGTGAC-3'; reverse primer: 5'- GTCACCCTCAACTACCATCTGACTG-3'). We amplified a 2180-bp fragment of mouse b2-microglobulin RNA (forward primer: 5' -CTCGCGCTACTCTCTTCTCTTTCTGG-3'; reverse primer: 5'- GCTTACATGTCTCTGATCCCACTTAA-3') and a 120-bp fragment of human b2-microglobulin (forward primer: 5'- ACCCCCACTGAAAAAGATGA-3'; reverse: 5'- ATCTTCAAACCTCCATGATG-3'). Fold-changes were calculated relative to DMSO- treated control samples.

\section{Western blots}

Cells were lysed in a buffer containing $20 \mathrm{mM}$ Tris $\mathrm{HCl}, \mathrm{pH} 8.0,137 \mathrm{mM} \mathrm{NaCl}, 1 \% \mathrm{NP}-40,10 \%$ glycerol, $1 \mathrm{mM} \mathrm{Na}_{3} \mathrm{VO}_{4}, 1 \mathrm{mM}$ PMSF, $1 \%$ aprotinin, and $20 \mu \mathrm{g} / \mathrm{ml}$ leupeptin. Protein concentrations were determined using the Løwry method. For whole cell lysates, Laemmeli sample buffer was added and the samples were boiled. Equal amounts of protein were separated by SDS-PAGE. The proteins were blotted to PVDF membranes and probed with antibodies for RKIP (Cat \#37-3300, Zymed Laboratories, Invitrogen Corporation, Carlsbad, CA). Densitometry was performed using Scion Image (Scion Corporation, Frederick, MD). RKIP amounts were equalized relative to $\beta$-actin. All blots were repeated at least twice.

\section{Transient transfection and promoter activity}

RWPE-1 cells (50,000 cells/well) were plated in a 12-well plate with complete K-SFM medium $24 \mathrm{~h}$ before transfection. These cells were transfected with $0.4 \mu \mathrm{g}$ of both luciferase reporter plasmid containing RKIP promoter fragments [21] or a basic reporter plasmid (pRL-TK, Promega, Madison, WI) per well using Lipofectamine Plus@ reagent (Invitrogen, Carlsbad, CA) or Transfast@ (Promega, Madison, WI) according to manufacturer's guidelines. $24 \mathrm{~h}$ post transfection, cells were washed and fed with fresh medium with $0.001 \%$ DMSO or with DHT ( $5 \mathrm{nM}, 10 \mathrm{nM}$ ), and the incubations were continued for an additional $24 \mathrm{~h}$.

For luciferase assays, cells were harvested by removing the medium, washing the cells once with PBS, and incubating with $100 \mu$ l passive buffer (Promega, Madison, WI) for $1 \mathrm{~h}$ at room temperature. Both firefly and Renilla LUC activity were determined in a luminometer (LUM/star, BMG Lab Technologies, Inc., Durham, NC) using the dual-luciferase reporter assay system (Promega, Madison, WI). Fold changes were calculated relative to DMSO control-treated samples. All experiments were performed in triplicate.

\section{Electrophoretic Mobility Shift Assay (EMSA)}

Nuclear extracts from RWPE-1 were prepared and used for EMSA as previously described [22]. Nuclear extracts were prepared from cells treated with vehicle ( $0.1 \%$ ethanol), $5 \mathrm{nM} \mathrm{DHT}$ for $30 \mathrm{sec}, 1 \mathrm{~h}$, or $2 \mathrm{~h}$ before harvesting. EMSA was carried out using a gel shift assay system (Promega, Madison, WI). Nuclear protein $(10 \mu \mathrm{g})$ was incubated with gel shift binding buffer [10 mM HEPES, 10\% glycerol, $1 \mathrm{mM}$ dithiothreitol, $1 \mathrm{mg}$ 
of poly(dI-dC) per $10 \mathrm{ml}$, and $5 \mathrm{mg}$ of BSA per $10 \mathrm{ml}$ ] and a putative ARE consensus oligonucleotide probe labeled with $[\gamma-32 \mathrm{P}] \mathrm{ATP}$ by T4 polynucleotide kinase. The putative ARE consensus oligonucleotide having sequences (5'-CCTTGTCCAGGATGGTCTCAAAC-3') corresponding to the region between -571 to -557 of the RKIP promoter were synthesized by Invitrogen (Carlsbad, CA) and used as probe. The reaction was allowed to proceed for $30 \mathrm{~min}$ at room temperature. For cold competition experiments, the extract was preincubated for 30 min with 10-, 20-, or 100-fold molar excess of unlabeled oligonucleotide or 100-fold excess of SP1 oligonucleotide. For the antibody supershift assay, $1 \mu \mathrm{g}$ of anti-AR antibody (PG-21, Upstate, Lake Placid, NY) was incubated with the nuclear extracts for $30 \mathrm{~min}$ at room temperature prior to the addition of labeled probe. DNA-protein complexes were separated under nondenaturing condition in a $6 \%$ polyacrylamide gel (29:1) containing $2.5 \%$ glycerol. Gels were transferred to Whatman paper on a gel dryer, exposed to a BioRad GS-250 screen overnight, and then analyzed on a Bio-Rad molecular imager. Bands form dried EMSA gels were quantified by the STORM 860 PhosphorImager (Molecular Dynamics).

Chromatin Immunoprecipitation (ChIP)

ChIP experiments were performed in RWPE-1 cells according to the protocol described previously $[23,24]$. Briefly, RWPE-1 cells were grown in dishes of $100-\mathrm{mm}$ diameter and stimulated with different concentrations of DHT for $24 \mathrm{~h}$. Cells were washed twice with PBS, cross-linked with $1 \%$ formaldehyde, sonicated, pre-cleared, and incubated with $3 \mu \mathrm{g}$ isotype IgG or AR antibody (Santa Cruz, sc-816) overnight. Immunocomplexes were washed with low and high salt buffers sequentially, and DNA was eluted, reversed with $1 \%$ SDS solution and purified with a Qiagen PCR product purification kit. The enrichment of the DNA template was analyzed by real-time PCR with FastStart Universal SYBR Green Master (Roche) on an ABI $7900 \mathrm{HT}$ detector. For the predicted ARE in the RKIP promoter region, primer pairs targeting -573 to -515 are 5'- ACCTTGTCCAGGATGGTCTCA-3' (forward) and 5'- GGAGGCCAAAGCAGGAAGAT-3' (reverse). For the predicted ARE upstream of the RKIP promoter region, primer pairs targeting -3846 to 3871 are 5'AATATGAGTGACCATGGCCTATGA-3' (forward) and 5'-ACCACCTTGCACACATTTTCC -3' (reverse).

\section{Statistical analysis}

Student's t-test was used to examine DHT effects on RKIP expression. A ratio of promoter activities in the presence and absence of DHT was used as a dependent variable to avoid variation in basal activity between experiments.

\section{Animals}

Animal care and procedures were as described previously. Briefly, approximately 6-8 weeks average age of C57BL/ 6 male mice purchased from Charles River (Wilmington, MA) were housed and maintained by the University of Michigan Unit for Laboratory Animal Medicine (Ann Arbor, MI). Castration/ orchidectomy and killing of the mice were performed in a room dedicated to animal surgery according to a protocolapproved by the University of Michigan Animal Care and Use Committee (Ann Arbor, MI). Castrations consisted of removal of the testis, fat pad, and epididymis via scrotal incision. Sham castrated mouse served as control. All procedures were performed under anesthesia and were approved by the University of Michigan's Animal Care and Ethics Committee. At various times after castration, at least five mice were killed and their prostate, lung, brain, spleen, stomach, liver, and muscle were harvested, washed in cold phosphate-buffered saline (PBS) and snap-frozen in liquid nitrogen before being transferred to a $-70^{\circ} \mathrm{C}$ freezer.

\section{Results}

To determine if RKIP expression in the prostate is regulated by androgen, we used RWPE-1 cells as our normal prostate model system. RWPE-1 cells are immortalized nonneoplastic adult human prostatic epithelial cells from a white male donor [25]. RWPE-1 cells express wild-type androgen receptor (AR) and exhibit growth and differentiation characteristics of normal prostate epithelium. Therefore, RWPE-1 provides a useful cell culture model for studies on gene regulation in prostate epithelia.

RWPE-1 cells were treated with increasing concentrations of dihydrotestosterone (DHT) that include values in the physiological range of 1 to $10 \mathrm{nM}$. In preliminary experiments we 


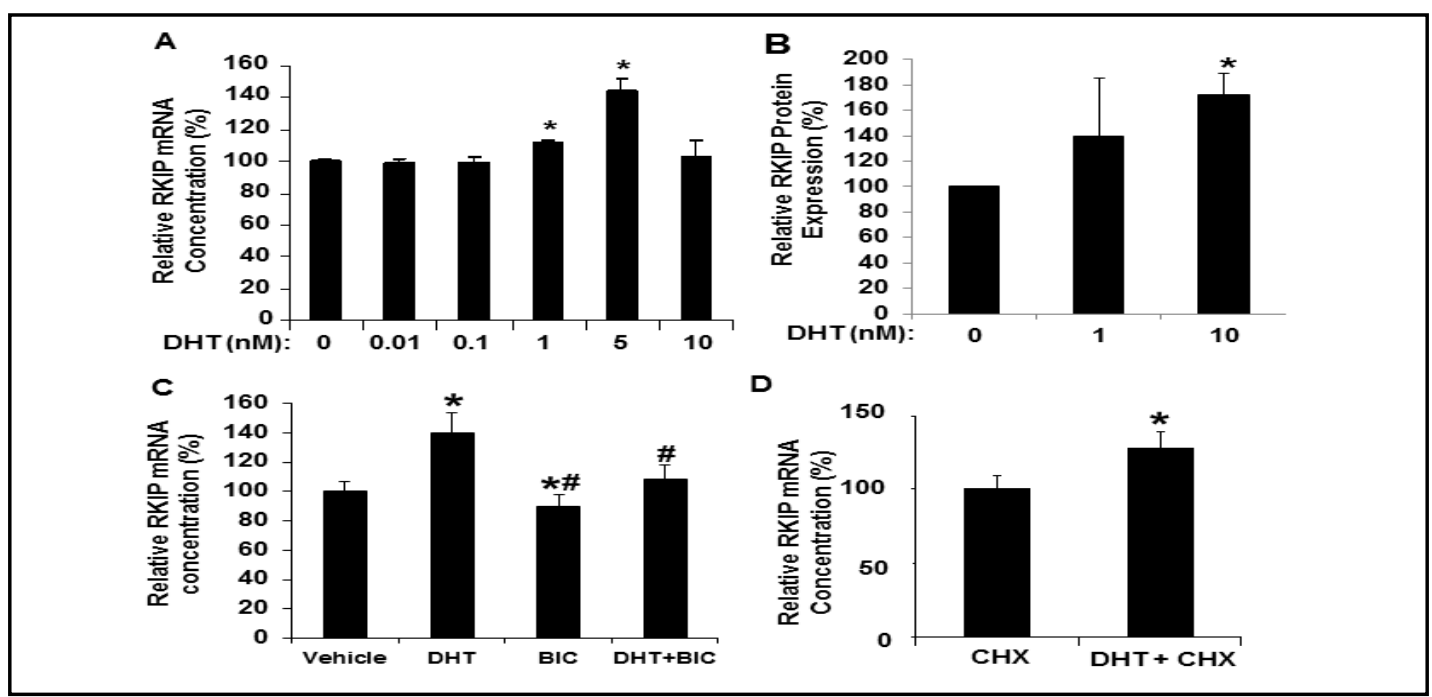

Fig. 1. RKIP expression is upregulated by androgen in normal prostate epithelial cells. (A) RWPE-1 cells were treated for $24 \mathrm{~h}$ with increasing concentrations of DHT. Total RNA was collected and subjected to real time RT-PCR to determine the relative amounts of RKIP mRNA. $\beta$-globulin was used as a control. $\left({ }^{*} \mathrm{P}<0.05\right.$ versus DHT $0 \mathrm{nM}$ ). (B) RWPE-1 cells were treated with varying concentrations of DHT for 24 hrs. Total protein was collected then subjected to western analysis for RKIP. The bands were subjected to densitometry. DHT at 0 $\mathrm{nM}$ was set as one and results are shown relative to this amount $\left({ }^{*} \mathrm{P}<0.02\right.$ vs. DHT $\left.0 \mathrm{nM}\right)$. (C) RWPE- 1 cells were treated for $24 \mathrm{~h}$ with DHT $(5 \mathrm{nM})$, BIC $(10 \mu \mathrm{M})$ (bicalutamide), or DHT + BIC. Total RNA was collected and subjected to RT-PCR to quantify RKIP mRNA. ( ${ }^{*} \mathrm{P}<0.05$ vs. vehicle and ${ }^{*} \mathrm{P}=0.003$ vs. DHT). (D) RWPE-1 cells were treated with cyclohexamide (CHX) $(0.5 \mu \mathrm{g} / \mathrm{ml})$ in the presence or absence of DHT (5 nM) for 24 hours. Real time RT-PCR was performed to determine the relative amounts of RKIP RNA ( ${ }^{*} \mathrm{P}<0.04$ vs. CHX alone). Results are presented as mean \pm SD from three repeated experiments.

Fig. 2. DHT activates the RKIP promoter. RWPE-1 cells were transfected with luciferase reporter vectors driven by the RKIP promoter. Cells were treated with the indicated amounts of DHT and luciferase levels were measure $24 \mathrm{~h}$ later. Results are shown as mean \pm SD luciferase levels of 3 independent experiments. ${ }^{*} \mathrm{P}<0.05$ vs. untreated cells.

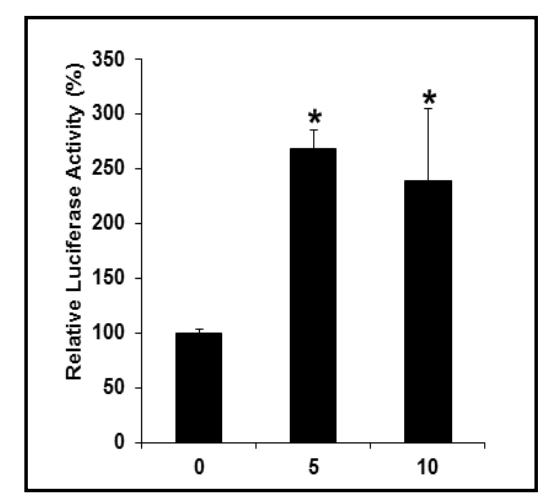

determined that $24 \mathrm{~h}$ stimulation results in maximal induction (data not shown); thus, we evaluated RKIP expression after $24 \mathrm{~h}$ of incubation with DHT. After DHT treatment, total RNA was analyzed by real time RT-PCR for human RKIP mRNA expression. DHT caused a dosedependent increase in RKIP mRNA expression (Fig. 1A). A maximum induction of 1.5-fold was seen at $5 \mathrm{nM}$. A very low concentration of DHT ( $0.1 \mathrm{nM})$ showed almost no induction of RKIP expression; this concentration is close to the $\mathrm{K}_{\mathrm{d}}$ value of DHT for the androgen receptor. However, $1 \mathrm{nM}$ DHT induced a significant increase in RKIP mRNA (Fig. 1A). This pattern of induction very closely follows the expected binding kinetics of DHT to the androgen receptor [26]. These results indicate that the level of RKIP mRNA expression is induced by androgens in a concentration-dependent manner.

To confirm that the increase in RKIP mRNA seen in RWPE-1 cells treated with DHT translated into changes in protein expression, we probed western blots of protein from 


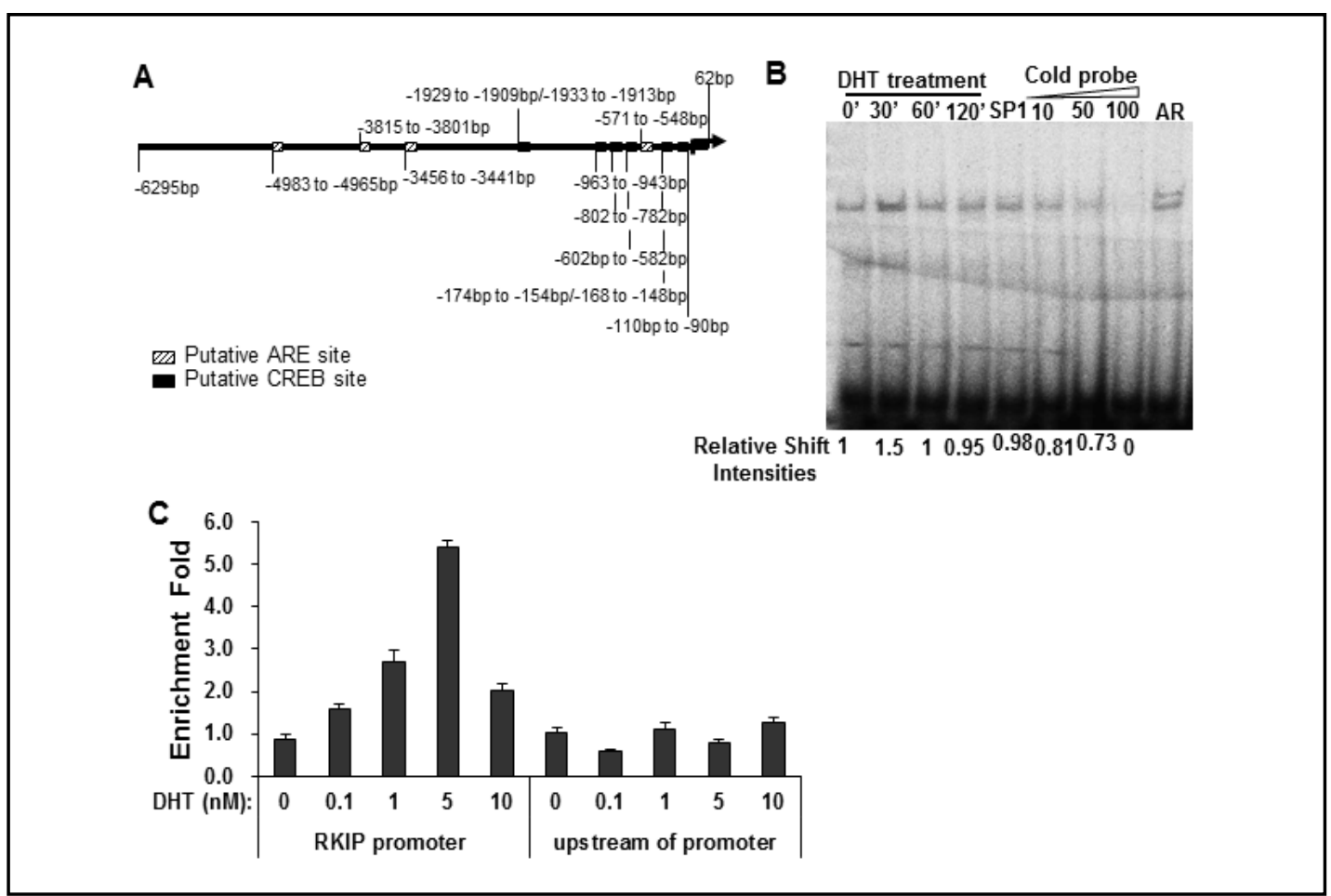

Fig. 3. AR binds directly to the -571 RKIP ARE. (A) Schematic of RKIP promoter with putative ARE and CREB sites indicated. (B) RWPE-1 cells were treated with DHT for 30 min then nuclear proteins were collected and subjected to an EMSA assay using the -571 RKIP ARE as a probe (lanes 1-4). Lane 5 uses the SPI oligo at 100-fold excess as a non-specific competitor. Lanes 6-8 use increasing amounts of non-radioactive ARE as a competitor. Lane 9 is a supershift of the complex using anti-AR antibody binding. Densitometry was performed using Scion Image to confirm the increased shift at $30 \mathrm{~min}$ as indicated by the relative shift intensities at the bottom of the Figure. (C) ChIP analysis of AR recruitment to the RKIP promoter following stimulation of cells with DHT. RWPE-1 cells were treated with DHT of the indicated concentration for 24 hrs. CHIP assays were performed to detect the AR binding to the predicted AR elements (AREs). Primers targeting the AREs in the RKIP promoter region or upstream of the RKIP promoter are used. The DNA enrichment was normalized to isotype IgG. Each PCR reaction was performed in triplicate with each experiment repeated at least three times independently. Values are presented as means \pm SDs.

DHT-treated RWPE-1 cells for RKIP. In concordance with the mRNA data, DHT increased the amount of RKIP protein by 1.7-fold (Fig. 1B).

To verify that DHT alters RKIP expression through the AR, we blocked AR activity using the antiandrogen bicalutamide. Bicalutamide binds to the AR and prevents the activation of the AR by androgen. The addition of bicalutamide inhibited DHT-mediated induction of RKIP mRNA expression (Fig. 1C). Although some androgen-induced genes are regulated directly by androgen and its ligand, AR, others are induced through indirect mechanisms by which androgens increase the expression of an unknown intermediate protein that directly induces the expression of target genes. To test if androgen requires production of an intermediate protein to stimulate RKIP expression, we repeated the treatment of $5 \mathrm{nM}$ DHT for $24 \mathrm{~h}$ with or without the potent protein synthesis inhibitor cycloheximide (CHX). Cells treated with CHX still responded to DHT treatment with an increase in RKIP expression (Fig. 1D). These results demonstrate that de novo protein synthesis is not required for androgen induction of RKIP.

To examine the effect of androgen on RKIP promoter activity, we transfected RWPE-1 cells with a luciferase reporter plasmid containing the human RKIP promoter fragments from -2206 to $-26 \mathrm{bp}$ [21]. The cells were incubated with either vehicle (DMSO) or DHT (5 nM, and $10 \mathrm{nM}$ ) for $24 \mathrm{~h}$. DHT induced over 2.5 -fold activation of the RKIP promoter compared 

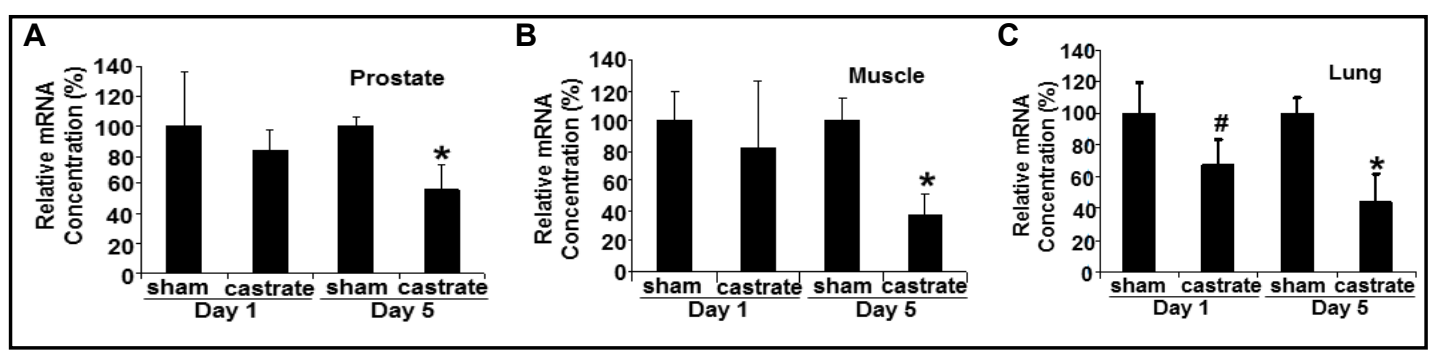

Fig. 4. RKIP expression is decreased in castrated mice. 6-8 week old male mice ( $N=5 /$ group) were castrated or sham castrated then sacrificed 1 and 5 days post-castration. Total RNA was collected from a variety of organs including prostate (A), muscle (B), and lung $(C)$ were subjected to real time RT-PCR to determine RKIP mRNA expression. Results are shown as mean \pm SD relative mRNA levels. $\# \mathrm{P}=0.046,{ }^{*} \mathrm{P}<0.009$ vs. sham day 5.

to the activity in vehicle-treated cells (Fig. 2). The DHT-responsive activity was comparable for both plasmids. These data indicate that DHT induces RKIP mRNA production, at least in part, through activation of RKIP promoter transcription.

Examination of human RKIP promoter revealed the presence of four putative androgenresponse elements (ARE) $[27,28]$ of which only one was within the region represented by our promoter construct (Fig. 3A). A 15-bp sequence (5'-TGTCCAggaTGGTCT-3') with significant homology (80\%) to the consensus ARE, 5'-GGA/TACAnnnTGTTCT-3' [27, 28], is located between base pairs -571 and -548 relative to the putative transcriptional start site, and is present in the promoter sequence utilized for the RKIP promoter luciferase assays (Fig. 3A).

To confirm the ability of DHT-activated AR to bind to the putative ARE sequence between -571 and -548 of the RKIP promoter we performed EMSA using the ARE sequence found in the RKIP promoter. DHT induced DNA binding activity was detected as early as 30 min following DHT treatment (Fig. 3B). Specificity of AR protein binding to the RKIP ARE was confirmed using three different approaches: (1) SP1 oligonucleotide (nonspecific competitor (lane 5)), which did not compete away the AR binding; (2) competition using 100-fold excess unlabeled putative RKIP ARE oligonucleotide (specific competitor (lane 8), which was able to compete away the AR binding; and (3) supershift of the protein/DNA complex with an antibody to the AR DNA binding domain (lane 9) that demonstrated that the shifted band contained the AR.

We next used quantitative ChIP assays to determine whether DHT treatment stimulates the binding of AR to the promoter of RKIP in the cells (Fig. 3C). The RWPE-1 cells were incubated with either vehicle (DMSO) or DHT for $24 \mathrm{~h}$. The cross-linked and sonicated chromatin prepared from RWPE-1 cells was immunoprecipitated with antibodies specific to either AR or rabbit IgG serum (control), and the amount of promoter DNA associated with the IP chromatin was quantitated by quantitative real-time PCR with primers specific to the human RKIP promoter regions. These ChIP PCR primers were made to DNA sequences situated near potential ARE sites in the human RKIP ( -573 to $-515 \mathrm{bp})$ promoter regions. This quantitative ChIP assay showed that endogenous AR binding to this site was strongly induced upon the addition of DHT to RWPE-1 cells. We also performed control ChIP assays to analyze for the presence of upstream region ( -3846 to $-3871 \mathrm{bp}$ ) from RKIP promoter by quantitative real-time PCR. This region contains a putative ARE (Fig. 3A). Consistent with the specificity of our ChIP assays, this control ChIP experiment demonstrated that neither AR antibody nor IgG serum immunoprecipitated significant levels of the putative AREs upstream from the RKIP promoter. Taken together, these results demonstrate that upon DHT treatment AR is recruited to the putative ARE present within the RKIP promoter.

To determine whether RKIP was regulated by androgen in vivo, we examined RKIP expression level in response to castration in 6-8 week old C57BL/6 male mice. RNA was extracted from various organs previously shown to express RKIP $[8,9]$ on day 1 or day 5 , after castration. Real-time RT-PCR analysis revealed that $24 \mathrm{hr}$ after castration, the steady- 
state levels of RKIP mRNA began decreasing in prostate tissue (Fig. 4A). By day 5, the RKIP expression level was significantly decreased. These data suggested that the maintenance of a high level of expression of RKIP in prostate requires androgen. In addition, RKIP levels were markedly decreased (2-3-fold) by day 5 after castration in muscle and lung (Fig. 4B and 4C), but not in the other organs we examined, such as brain, liver, spleen, and stomach (not shown). The above observation suggested that the effect of androgen withdrawal on RKIP expression level is tissue-specific and further supported the notion that androgens regulate RKIP expression.

\section{Discussion}

Since the initial identification of RKIP, numerous groups have focused on exploring its functions. Collective evidence indicates that RKIP functions as a multi-faceted regulator controlling various cellular processes including cell differentiation, the cell cycle, apoptosis and cell migration [29]. Our previous work defining it as a novel metastatic suppressor and an effector of signal transduction pathway leading to apoptosis highlights its great potential for clinical intervention in the treatment of cancer. However, the regulation of RKIP expression has not been well characterized. In the current study, we provide several lines of both in vitro and in vivo evidence that androgens induce RKIP expression in the prostate. This is the first demonstration of endocrine regulation of the metastasis suppressor gene RKIP.

The classical mechanism of androgen-mediated gene expression involves the direct interaction of androgen with the androgen receptor (AR) protein, resulting in AR's nuclear translocation and binding to cis-acting androgen-responsive elements (ARE) on androgen target genes [30]. Binding to these AREs facilitates interactions with the general transcriptional machinery leading to gene transcription. AR activity can be modified by coactivators and co-repressors that bind the AR [reviewed in 31,32]. Androgens also can affect gene expression through posttranscriptional [33] and genome-independent mechanisms [34]. Alternatively, androgen target genes may be regulated indirectly: as a secondary or tertiary event through the initial direct up-regulation or liberation of a transcription factor(s) that, in turn, regulates the expression of other target genes [35]. The data presented here indicate that androgen regulates RKIP expression in a dose-dependent manner. The induction of RKIP could be blocked by the anti-androgen reagent, bicalutamide, confirming that androgen regulates RKIP expression through the AR. In addition, cycloheximide experiments indicate that the induction of RKIP by androgens does not require de novo protein synthesis, suggesting that the expression of these transcripts is regulated directly by androgen, rather than through intermediary transcription factors. In agreement with above observations, the RKIP promoter responded directly to androgen stimulation. Furthermore, regulation of RKIP transcription appears to be mediated via a trans-acting factor since exogenous RKIP promoters are regulated in a similar fashion to their endogenous counterparts.

Given that most AREs conform to a consensus sequence composed of two 6-base asymmetrical elements separated by three spacer nucleotides; 5'-AGAACAnnnTGTTCT-3', we have identified a putative ARE in the promoter region of RKIP, which shares $80 \%$ homology with the ARE consensus sequence. EMSA demonstrated that protein from RWPE1 nuclear extracts formed a complex with the putative RKIP ARE. Supershift and competition experiments confirmed that the identity of the protein is AR. Taken together, these data suggest that the ARE in the RKIP promoter region mediates androgen responsiveness of the RKIP promoter through the AR.

Cell-based model systems may not accurately reflect what occurs in vivo. We, therefore, tested the concept in an animal model and found that castration reduced RKIP expression, which provides in vivo evidence to corroborate the notion that androgens transcriptionally regulate RKIP expression in the prostate. Collectively, the data presented here support a mechanism of direct, rather than indirect, transcriptional control of RKIP expression by androgens in normal prostate epithelial cells. 
Primary PCa is largely dependent on androgens for growth and survival but responds favorably to androgen ablation and antiandrogen therapy in most patients. However, this therapy eventually fails, leaving patients with an androgen-independent tumor for which there is no effective therapy $[36,37]$. We determined that a loss of RKIP was associated with PCa progression [18] by examining the patterns of RKIP expression during PCa initiation, progression, and metastasis. Immunohistochemical staining using polyclonal antibody against RKIP revealed that the RKIP protein was expressed in normal prostate epithelia, as well as in benign prostatic hyperplasia (BPH) $[7,18,19]$. RKIP expression was noticeably reduced and the staining was heterogeneous in primary $\mathrm{PCa}$; whereas, metastases were RKIP negative or contained weak RKIP staining [18].

The mechanisms through which RKIP have recently drawn much attention. Alteration in gene expression can often occur through several mechanisms: hypermethylation, gene deletion, transcriptional or post-transcriptional regulation, etc. In colorectal cancers, there has been suggested that hypermethylation leads to loss of RKIP expression in advanced primary cancers and metastatic tissue [38-40]. We previously reported that the methylation inhibitor 5-Aza-2dC had no effect on RKIP expression in DU-145 PCa cells [21] indicating that hypermethylation is not a likely cause of repressed RKIP expression in advanced PCa. In one instance, loss of RKIP was associated with genomic instability [38]. We performed allelotyping of LNCaP, C4-2B, PC-3 and DU-145 prostate cancer cell lines and observed that two RKIP alleles were present in them all indicating that lower RKIP expression was not due to chromosomal deletion (data not shown). Furthermore, we have identified that Snail, a zinc-transcriptional repressor, mediates repression of RKIP expression in advanced PCa [21]. A recent study has reported that microRNA-224 inhibits RKIP gene expression by directly targeting its 3'-untranslated region in human breast cancer cells [41]. Polycomb protein enhancer of zeste homolog 2 (EZH2) was shown to negatively regulated RKIP transcription through repression-associated histone modification [42]. In addition, flavonoid didymin, a naturally occurring compound that is richly expressed in citrus fruits, induced RKIP expression in neuroblastoma [43]. Here, we demonstrate that RKIP is upregulated by androgen in normal prostate cells, raising the possibility that their expression in tumors may decrease during androgen ablation therapy, during PCa progress and loss of AR responsiveness, providing a growth advantage to tumor cells and facilitating metastasis. This possibility is under investigation.

In conclusion, this paper describes the androgen regulation of RKIP. Androgen alters RKIP expression through AR-mediated transcriptional modulation of the RKIP promoter. These data suggest that manipulations of the androgen axis may mediate loss of RKIP in PCa and enhance metastasis. This is the first demonstration of endocrine regulation of the metastasis suppressor gene RKIP.

\section{Acknowledgements}

The work was supported by grants from the US Department of Defense Prostate Cancer Research Program (PC094435 to Z.F.) and National Institutes of Health (CA098513 to E.T.K.).

\section{References}

1 Simister P, Banfield M, Brady R: The crystal structure of PEBP-2, a homologue of the PEBP/RKIP family. Acta Crystallogr D Biol Crystallogr 2002;58:1077-1080.

2 Banfield M, Barker J, Perry A, Brady R: Function from structure? The crystal structure of human phosphatidylethanolamine-binding protein suggests a role in membrane signal transduction. Structure 1998;6:1245-1254. 


\section{Cellular Physiology $\quad$ Cell Physiol Biochem 2012;30:1340-1350 and Biochemistry

- 3 Yeung K, Seitz T, Li S, Janosch P, McFerran B, Kaiser C, Fee F, Katsanakis K, Rose D, Mischak H, Sedivy JM, Kolch W: Suppression of Raf-1 kinase activity and MAP kinase signalling by RKIP. Nature 1999;401:173-177.

4 Bernier I, Jollès P: Purification and characterization of a basic 23 kDa cytosolic protein from bovine brain. Biochim Biophys Acta 1984;790:174-181.

5 Perry A, Hall L, Bell A, Jones R: Sequence analysis of a mammalian phospholipid-binding protein from testis and epididymis and its distribution between spermatozoa and extracellular secretions. Biochem J 1994;301:235-242.

6 Tohdoh N, Tojo S, Agui H, Ojika K: Sequence homology of rat and human HCNP precursor proteins, bovine phosphatidylethanolamine-binding protein and rat 23-kDa protein associated with the opioid-binding protein. Brain Res Mol Brain Res 1995;30:381-384.

7 Al-Mulla F, Hagan S, Behbehani AI, Bitar MS, George SS, Going JJ, Garcia JJ, Scott L, Fyfe N, Murray GI, Kolch W: Raf kinase inhibitor protein expression in a survival analysis of colorectal cancer patients. J Clin Oncol 2006;24:5672-5679.

8 Bollengier F, Mahler A: Localization of the novel neuropolypeptide h3 in subsets of tissues from different species. J Neurochem 1988;50:1210-1214.

-9 Frayne J, Ingram C, Love S, Hall L: Localisation of phosphatidylethanolamine-binding protein in the brain and other tissues of the rat. Cell Tissue Res 1999;298:415-423.

10 Moffit JS, Boekelheide K, Sedivy JM, Klysik J: Mice lacking Raf kinase inhibitor protein-1 (RKIP-1) have altered sperm capacitation and reduced reproduction rates with a normal response to testicular injury. J Androl 2007;28:883-890.

11 Ojika K, Mitake S, Tohdoh N, Appel S, Otsuka Y, Katada E, Matsukawa N: Hippocampal cholinergic neurostimulating peptides (HCNP). Prog Neurobiol 2000;60:37-83.

12 Vallee BS, Tauc P, Brochon JC, Maget-Dana R, Lelievre D, Metz-Boutigue MH, Bureaud N, Schoentgen F: Behaviour of bovine phosphatidylethanolamine-binding protein with model membranes. Evidence of affinity for negatively charged membranes. Eur J Biochem 2001;268:5831-5841.

13 Yeung K, Janosch P, McFerran B, Rose D, Mischak H, Sedivy J, Kolch W: Mechanism of suppression of the Raf/MEK/extracellular signal-regulated kinase pathway by the raf kinase inhibitor protein. Mol Cell Biol 2000;20:3079-3085.

14 Yeung K, Rose D, Dhillon A, Yaros D, Gustafsson M, Chatterjee D, McFerran B, Wyche J, Kolch W, Sedivy J: Raf kinase inhibitor protein interacts with NF-kappaB-inducing kinase and TAK1 and inhibits NF-kappaB activation. Mol Cell Biol 2001;21:7207-7217.

15 Lorenz K, Lohse MJ, Quitterer U: Protein kinase C switches the Raf kinase inhibitor from Raf-1 to GRK-2. Nature 2003;426:574-579.

16 Al-Mulla F, Bitar MS, Al-Maghrebi M, Behbehani AI, Al-Ali W, Rath O, Doyle B, Tan KY, Pitt A, Kolch W: Raf kinase inhibitor protein RKIP enhances signaling by glycogen synthase kinase-3beta. Cancer Res 2011;71:13341343.

17 Al-Mulla F, Bitar MS, Feng J, Park S, Yeung KC: A new model for raf kinase inhibitory protein induced chemotherapeutic resistance. PLoS One 2012;7:e29532.

18 Fu Z, Kitagawa Y, Shen R, Shah R, Mehra R, Rhodes D, Keller P, Mizokami A, Dunn R, Chinnaiyan A, Yao Z, Keller ET: Metastasis suppressor gene Raf kinase inhibitor protein (RKIP) is a novel prognostic marker in prostate cancer. Prostate 2006;66:248-256.

19 Fu Z, Smith P, Zhang L, Rubin M, Dunn R, Yao Z, Keller E: Effects of raf kinase inhibitor protein expression on suppression of prostate cancer metastasis. J Natl Cancer Inst 2003;95:878-889.

20 Lamont KR, Tindall DJ: Androgen regulation of gene expression. Adv Cancer Res 2010;107:137-162.

21 Beach S, Tang H, Park S, Dhillon AS, Keller ET, Kolch W, Yeung KC: Snail is a repressor of RKIP transcription in metastatic prostate cancer cells. Oncogene 2008;27:2243-2248.

22 Hellman LM, Fried MG: Electrophoretic mobility shift assay (EMSA) for detecting protein-nucleic acid interactions. Nat Protoc 2007;2:1849-1861.

-23 Shang Y, Hu X, DiRenzo J, Lazar MA, Brown M: Cofactor dynamics and sufficiency in estrogen receptorregulated transcription. Cell 2000;103:843-852.

24 Wang Y, Zhang H, Chen Y, Sun Y, Yang F, Yu W, Liang J, Sun L, Yang X, Shi L, Li R, Li Y, Zhang Y, Li Q, Yi X, Shang Y: LSD1 is a subunit of the NuRD complex and targets the metastasis programs in breast cancer. Cell 2009;138:660-672. 


\section{Cellular Physiology $\quad$ Cell Physiol Biochem 2012;30:1340-1350 and Biochemistry

-25 Bello D, Webber MM, Kleinman HK, Wartinger DD, Rhim JS: Androgen responsive adult human prostatic epithelial cell lines immortalized by human papillomavirus 18. Carcinogenesis 1997;18:1215-1223.

-26 Bonsing BA, Devilee P, Cleton-Jansen AM, Kuipers-Dijkshoorn N, Fleuren GJ, Cornelisse CJ: Evidence for limited molecular genetic heterogeneity as defined by allelotyping and clonal analysis in nine metastatic breast cancinomas. Cancer Res 1993;53:3804-3811.

-27 Cleutjens K, van Eekelen C, van der Korput H, Brinkmann A, Trapman J: Two androgen response regions cooperate in steroid hormone regulated activity of the prostate-specific antigen promoter. J Biol Chem 1996;271:6379-6388.

-28 Roche P, Hoare S, Parker M: A consensus DNA-binding site for the androgen receptor. Mol Endocrinol 1992;6:2229-2235.

-29 Zeng L, Imamoto A, Rosner MR: Raf kinase inhibitory protein (RKIP): a physiological regulator and future therapeutic target. Expert Opin Ther Targets 2008;12:1275-1287.

30 Prins G: Molecular biology of the androgen receptor. Mayo Clin Proc 2000;75: S32-35.

-31 Sampson ER, Yeh SY, Chang HC, Tsai MY, Wang X, Ting HJ, Chang C: Identification and characterization of androgen receptor associated coregulators in prostate cancer cells. J Biol Regul Homeost Agents 2001;15:123-129.

32 Mendelsohn LG: Prostate cancer and the androgen receptor: strategies for the development of novel therapeutics. Prog Drug Res 2000;55:213-233.

-33 Perry JE, Tindall DJ: Androgens regulate the expression of proliferating cell nuclear antigen posttranscriptionally in the human prostate cancer cell line, LNCaP. Cancer Res 1996;56:1539-1544.

34 Kousteni S, Bellido T, Plotkin L, O'Brien C, Bodenner D, Han L, Han K, DiGregorio G, Katzenellenbogen J, Katzenellenbogen B, Roberson PK, Weinstein RS, Jilka RL, Manolagas SC: Nongenotropic, sex-nonspecific signaling through the estrogen or androgen receptors: dissociation from transcriptional activity. Cell 2001;104:719-730.

-35 Swinnen J, Ulrix W, Heyns W, Verhoeven G: Coordinate regulation of lipogenic gene expression by androgens: evidence for a cascade mechanism involving sterol regulatory element binding proteins. Proc Natl Acad Sci USA 1997;94:12975-12980.

-36 Denis L, Murphy G: Overview of phase III trials on combined androgen treatment in patients with metastatic prostate cancer. Cancer 1993;72:3888-3895.

-37 Koivisto P, Kolmer M, Visakorpi T, Kallioniemi O: Androgen receptor gene and hormonal therapy failure of prostate cancer. Am J Pathol 1998;152:1-9.

-38 Al-Mulla F, Hagan S, Al-Ali W, Jacob SP, Behbehani AI, Bitar MS, Dallol A, Kolch W: Raf kinase inhibitor protein: mechanism of loss of expression and association with genomic instability. J Clin Pathol 2008;61:524-529.

-39 Minoo P, Zlobec I, Baker K, Tornillo L, Terracciano L, Jass JR, Lugli A: Loss of raf-1 kinase inhibitor protein expression is associated with tumor progression and metastasis in colorectal cancer. Am J Clin Pathol 2007;127:820-827.

40 Minoo P, Baker K, Goswami R, Chong G, Foulkes WD, Ruszkiewicz AR, Barker M, Buchanan D, Young J, Jass JR: Extensive DNA methylation in normal colorectal mucosa in hyperplastic polyposis. Gut 2006;55:1467-1474.

-41 Huang L, Dai T, Lin X, Zhao X, Chen X, Wang C, Li X, Shen H, Wang X: MicroRNA-224 targets RKIP to control cell invasion and expression of metastasis genes in human breast cancer cells. Biochem Biophys Res Commun 2012;425:127-133.

42 Ren G, Baritaki S, Marathe H, Feng J, Park S, Beach S, Bazeley PS, Beshir AB, Fenteany G, Mehra R, Daignault S, Al-Mulla F, Keller E, Bonavida B, de la Serna I, Yeung KC: Polycomb protein EZH2 regulates tumor invasion via the transcriptional repression of the metastasis suppressor RKIP in breast and prostate cancer. Cancer Res 2012;72:3091-3104.

43 Singhal J, Nagaprashantha LD, Vatsyayan R, Ashutosh, Awasthi S, Singhal SS: Didymin induces apoptosis by -inhibiting N-Myc and upregulating RKIP in neuroblastoma. Cancer Prev Res (Phila) 2012;5:473-483. 